\title{
Clinical Evaluation of Peroneous Brevis Muscle Flap as a Reconstructive Tool for Defects Around the Ankle
}

\author{
KHALED M. HASSAN, M.D.; AHMED M. MOHAMED, M.D. and MOSTAFA S. MOHAMED, M.B.B.Ch. \\ The Department of Plastic and Reconstructive Surgery, Faculty of Medicine, Minia University, Egypt
}

\begin{abstract}
Background: Soft tissue defects of the distal lower extremity are notoriously difficult wounds to treat. This is due to the paucity of soft tissue in this area and the thin integument as well as the relatively superficial tendons. Those defects often require local rotation flaps, the reverse flow flap or free tissue transfer. The success of local tissue rotation flaps can be improved with supercharging techniques; however, just as with free tissue transfers, these techniques require special surgical skills. One excellent alternative within the reconstructive spectrum of the lower leg is the distally based peroneus brevis muscle flap. This muscle flap is a viable option in properly selected patients for coverage of wounds about the ankle.
\end{abstract}

Patients and Methods: In this study, we used the distally based peroneous brevis muscle flap to reconstruct 20 cases of defects around the ankle. Cases presented to Plastic Surgery Department, Minia University Hospital in period between January to October 2017. Surgical procedure was performed under spinal anaesthesia in all cases. We followed cases for 6 months postoperatively.

Results: The mean age was 35 years old, 16 patients were males and 4 were female. $55 \%$ of patients had complete flap viability, $15 \%$ of cases had partial graft loss and $20 \%$ with partial flap necrosis and $10 \%$ of cases had complete flap loss.

Conclusion: We can suggest that the peroneus brevis muscle flap is an additional valuable option for reconstruction of defects around the ankle because of its adjacent location, reliability, and the relative simplicity of technique. The surgical technique is relatively easy, safe, and suitable for reconstruction of soft-tissue defects in a single stage.

Key Words: Peroneous brevis flap - Ankle defects.

\section{INTRODUCTION}

Soft tissue defects of the distal lower extremity are difficult wounds to treat due to paucity of soft tissue. This area of the leg has a thin integument, relatively superficial tendons that add to the difficulty of reconstruction. For these reasons, injuries often expose vital structures and leave the plastic surgeon with a difficult decision regarding appropriate wound management. Over the last several decades, microsurgical free-flap techniques looked to supplant pedicled muscle flaps for coverage of foot and ankle defects. However, other studies indicate that local flap options have seen resurgence in popularity, concurrent with a better understanding of lower leg vascular anatomy and improved wound care technology. Pedicled flaps afford the surgeon a reliable and relatively straight forward reconstructive option for patients with osteomyelitis or those who may not tolerate a larger operation. The usefulness of a muscle flap to cover exposed tendon and bone is not only from its ability to physically cover the defect, but also from its ability to introduce a new vascular bed to potentiate wound healing. Once the surgeon becomes comfortable in performing the anatomic dissection, harvesting and in setting, the pedicled muscle flap can be performed rapidly and with a high success rate [1].

The goals of reconstructive surgery include safety as well as restoration of form and function [2].

The donor site must also be considered when planning a reconstruction. Repair of a defect in one region by creating an equally problematic defect in the donor site is not a satisfactory tradeoff. Anatomic knowledge of the vascular territory of the donor muscle based on either dominant or segmental supply help to define which portion of the muscle can successfully be transferred or survive regional mobilization. Limitations of fascial harvest and muscle dissection can offer a functional benefit to certain donor regions and should be taken into account when designing the reconstruction [3].

Lower extremity wounds present a challenge for healing in the ankle region, the paucity of 
muscle and thin subcutaneous tissues often require local rotation flaps, the reverse flow flap or free tissue transfer [4].

In at-risk patients, these techniques can result in relatively high complication rates and significant donor site morbidity [5].

The success of local tissue rotation flaps can be improve with supercharging techniques; however, just as with free tissue transfers, these techniques require specialized surgical skills Furthermore, in many patients, these procedures are often not considered favorably [6].

The reverse peroneus brevis muscle is a viable option in properly selected patients for coverage of wounds about the ankle. It poses lower donor site morbidity and less risk in medically frail patients and is not as technically demanding as other flap techniques [7].

Abd-Al-Moktader (2015) stated that one excellent alternative within the reconstructive spectrum of the lower leg is the distally based peroneus brevis muscle flap [8]. The muscle was first described by Mathes and Nahai, and the first article showing the clinical use of the flap in 19 patients was by Eren and co-workers in 2001 [9].

Four years later, Yang and colleagues confirmed the classification of the flap as type IV through cadaver dissections and showed the possibility of mobilizing the muscle to cover the distal third of the lower leg without disturbing distal pedicles [9].

Thanks to its almost constant vascularity, and easy and quick elevation, with acceptable donorsite morbidity, the muscle flap provides sufficient tissue for covering small and moderate defects in the region of the lateral or medial malleolus or the distal Achilles tendon as well as when they extend deep into the ankle with exposure of osteosynthesis material, bone or tendons [15].

The overall success of the flap was reasonable. The cosmetic result was accepted and no functional impairment of the affected extremity occurs due to flap harvest. Function of foot eversion and plantar flexion as well as ankle functionality are maintained due to preservation of the peroneus longus muscle. Another strong point favoring the peroneus brevis flap is the low donor site morbidity. The possibly poorly vascularized tip of the flap should be revised. The presence of diabetes was not a limiting factor for using the flap.

\section{PATIENTS AND METHODS}

This is a prospective non randomized clinical study.

The study was conducted in the Plastic Surgery Department Minia University Hospital in the period from January to October 2018. It included 20 patients presented with defects around the ankle. We had approval of the Ethics Committee of Faculty of Medicine Minia University. All patients were counselled and signed an informed consent to share in the study.

\section{Exclusion criteria:}

All patients' categories are allowed into the study except patients with history of hematological disorders or chronic use of corticosteroid. Cases with defects larger than $7 \mathrm{~cm}$ in transverse diameter, those with scarred tissues at the muscle pedicle, too distant defects and chronic heavy smokers are also excluded from the study.

\section{Detection of arterial perforators:}

Color duplex was also performed preoperatively for detection of arterial perforators. Doppler ultrasound was also used pre or intra operatively to confirm and localize perforators.

\section{Operative technique:}

\section{1- Position:}

We put the patient in the supine position on operating table with internally rotated foot \& leg of the affected limb. In case of defects over posterior ankle or Achilles tendon, we put the patient in the prone position.

\section{2- Anaesthesia:}

All adult cases (15) operated by spinal anesthesia except children (5) by general anesthesia with endotracheal intubation.

\section{3- Wound debridement and wash:}

Careful debridement of the devitalized skin and subcutaneous tissues was done in all cases. The main reliable clinical sign of viability of the wound edges was the free marginal bleeding. Povidone iodine $7.5 \%$ + saline were used to clean the wounds and remove dirties to reduce the local bacterial count.

\section{4- Skeletal fixation:}

Fractures (if associated) were fixed primarily by the orthopedic team. 


\section{5- Flap elevation:}

Initially the most distal segmental vascular pedicle from the peroneal artery, which provides the arterial blood supply for the flap, was mapped by Doppler and marked. This segmental branch of the axial vessel, which also provides retrograde perfusion of the muscle by the posterior tibia artery, is usually located $4-5 \mathrm{~cm}$ proximal to the tip of the lateral malleolus. The technique was performed under tourniquet control. The tourniquet was released after flap elevation to check its vascularity.

Skin incision was made $1 \mathrm{~cm}$ dorsal to a line drawn from the head to the tip of the fibula from the mid leg, where the peroneus brevis muscle originates, to a point $3 \mathrm{~cm}$ above the tip of the fibula. Using loupe magnification, the peroneus brevis muscle was separated from the peroneus longus muscle.

After identifying the tendons of the peroneus longus and the peroneus brevis muscle and the superficial peroneal nerve, dissection of the peroneus brevis muscle from the lateral surface of the fibula starting proximal to distal taking the periosteum with the flap. Care was taken to preserve the superficial peroneal nerve when the motor branch to the peroneus brevis muscle was divided. In the distal third of the fibula, approximately $4-5 \mathrm{~cm}$ proximal of the lateral malleolus, the main muscle vascular pedicle, from the peroneal artery, enters the muscle consistently. This was dissected and preserved. After complete elevation, the proximal muscle belly was ready for transposition into adjacent distal defects. The tourniquet was then released, and hemostasis was achieved. In some cases, a subcutaneous tunnel was prepared to place the flap in the Achilles area or to the medial malleolus. After fixation with simple interrupted suture to the defect, the muscle flap was covered using split-thickness skin grafts. Suction drain was inserted in the donor site that is closed primarily by simple running sutures and the leg was dressed and secured using a posterior slab.

\section{6- Antibiotics:}

All patients received $3^{\text {rd }}$ generation cephalosporins and analgesics for 5 days postoperative.

\section{7- Anticoagulant:}

Patients received prophylactic dose of low molecular weight heparin for 5 days. We put patients on non-weight bearing regimen for 2 weeks. We encouraged oral fluids intake and advised to avoid smoking and cold exposure. Results were evaluated by clinical examination and photos both pre and postoperative by the researcher and supervisors to minimize bias. Patient's satisfaction was looked for by a questionnaire. They were asked to give their opinion about degree of pain, cosmetic appearance and the overall result of operation. Patients were followed-up for a period of 6 months.

\section{Statistical analysis:}

The collected data were coded, tabulated, and statistically analyzed using SPSS package version 25. Descriptive statistics were done for parametric quantitative data by mean, standard deviation and minimum\& maximum of the range, while they were done for categorical data by number and percentage. Graphical presentation was done using Microsoft excel 2016.

\section{RESULTS}

Our study included 20 patients. Sixteen cases were males (80\%), 4 cases were females $(20 \%)$. Age ranged from 10 to 55 years (mean 29). All the patients presented with defects around the ankle. Four cases with defect in the lateral ankle, 8 cases with defect in the medial aspect, 4 cases with defect on anterior aspect and 4 cases with defect over Achilles tendon as shown in Figs. $(1,2)$. Demographic and clinical Data of the study are shown in Tables $(1,2)$.

Six patients were smokers and 4 were diabetics. The etiology of defects was trauma in 14 patients, post burn raw area in 4 patients and exposed metals in 2 patients. Complete flap survival was noted in 14 cases $(70 \%)$. Two cases had complete flap necrosis and 4 had only distal necrosis (Table 3 ).

Area affected around the ankle as shown in (Table 3). Four cases were at anterior aspect, 4 cases at posterior aspect, 4 cases at lateral aspect and 8 cases at the medial aspect.

We had 4 cases (20\%) who had re operative cases. Three cases underwent split thickness skin graft and one case had full thickness skin graft. Operative time ranged from 90 to 120 minutes (Mean $=105)$. Post-operative complications included 2 cases with complete flap necrosis, 4 cases with partial flap necrosis, 3 cases with partial graft loss and 3 cases with infection.

Postoperative questionnaire showed that 13 patients $(65 \%)$ rated the overall results of operation as good and very good (Table 4). 

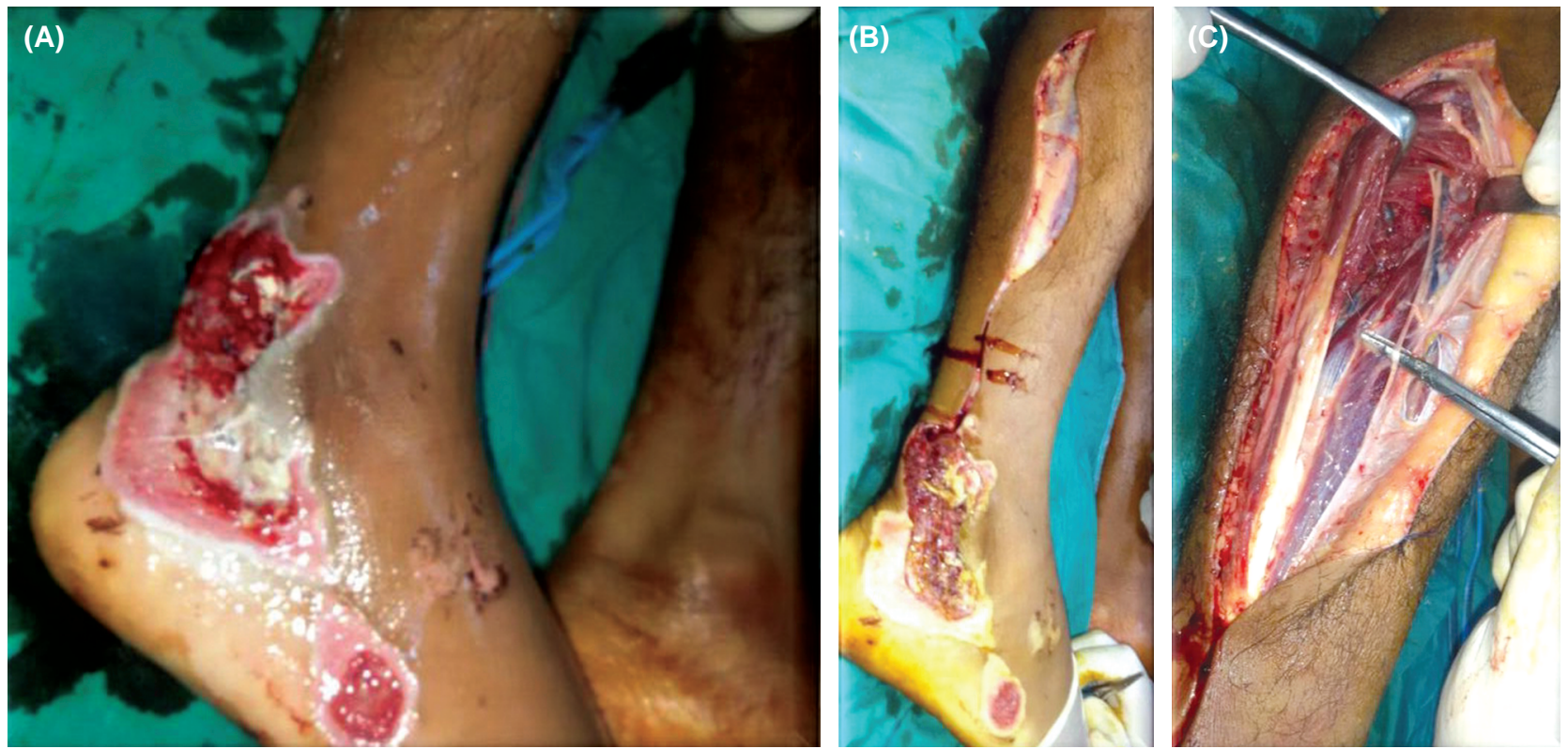
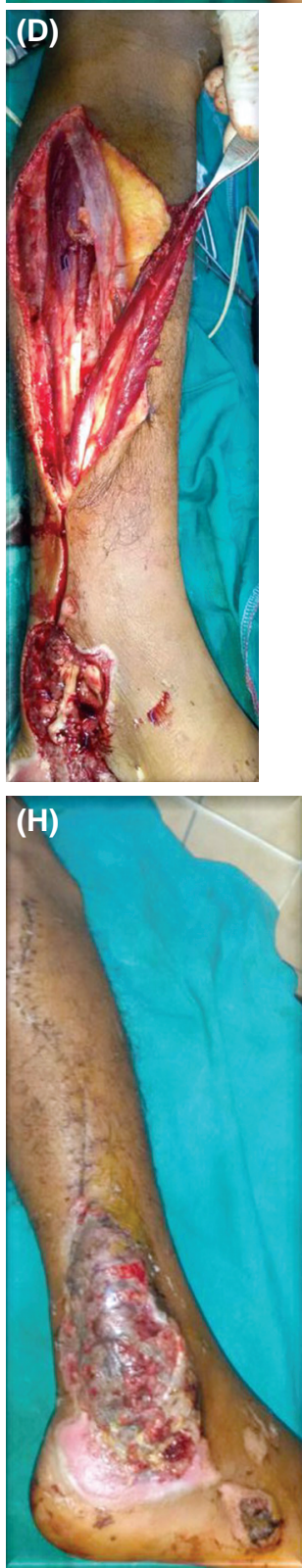
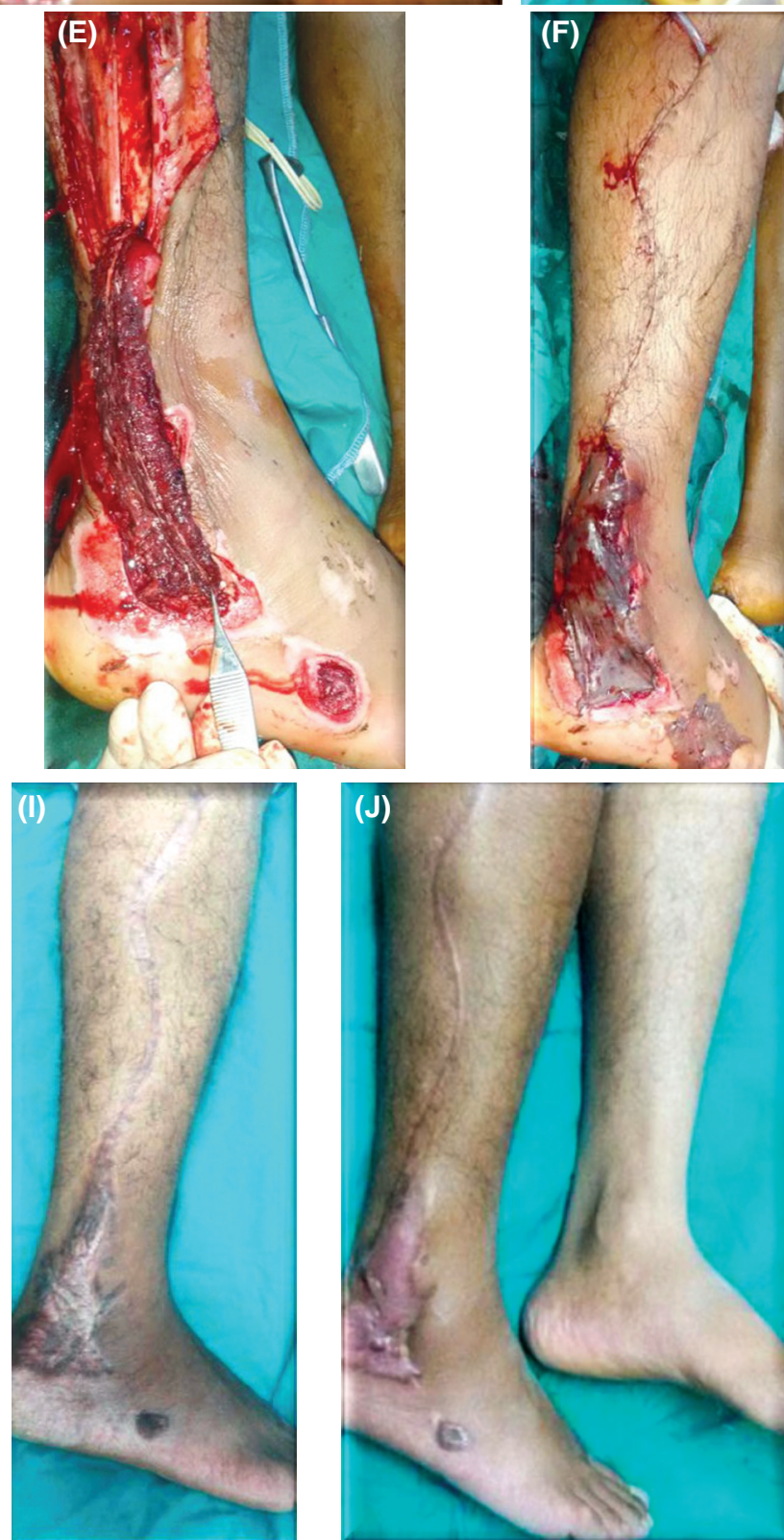

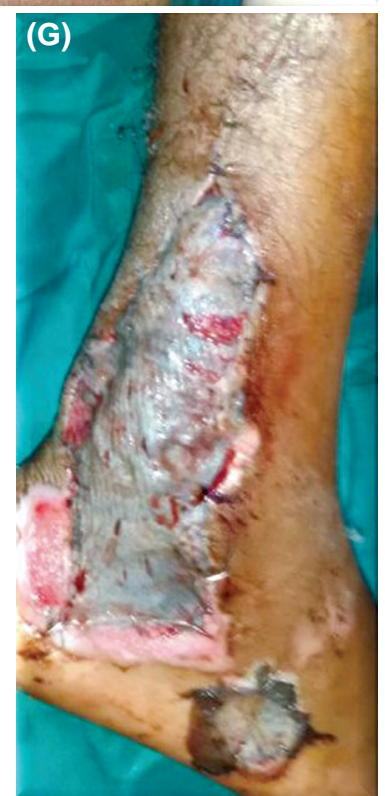

Fig. (1): (A) 20 year old $O^{\top}$ with post traumatic raw area on lateral aspect of right ankle and foot with exposed bone. (B) Lazy S skin incision over peroneus muscle. (C) Separation of peroneous longus from peroneous brevis. Scissor points to superficial peroneal nerve. (D) Elevation of distally based peroneus brevis muscle flap. (E) Inset of the flap to the defect. (F) Application of split thickness skin graft, donor site closed primary over tubal drain. (G) 3 days post-operative showing viable flap and graft. (H) 7 days post-operative. (I) 1 month postoperative. (J) 6 month post-operative. 

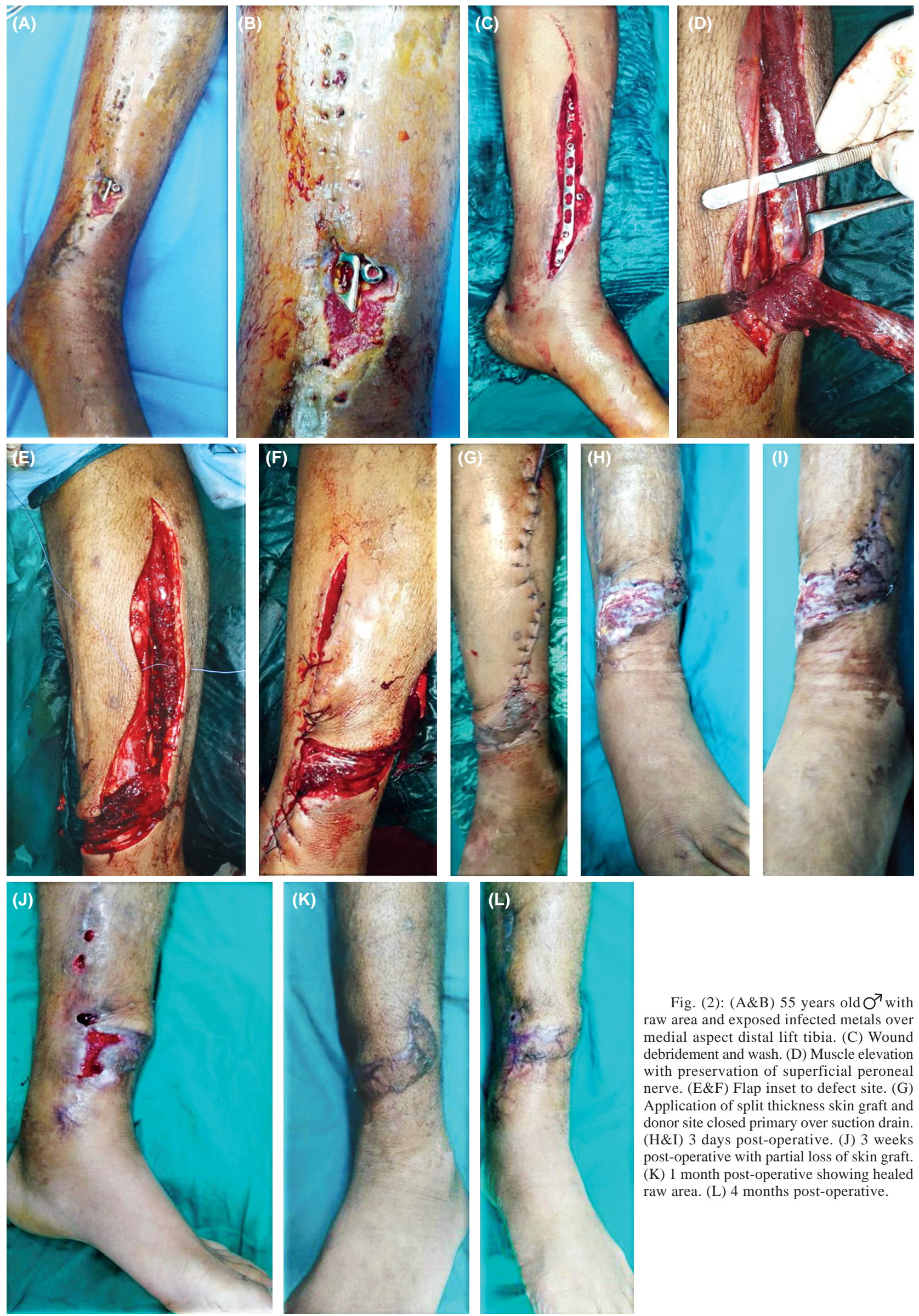

Fig. (2): (A\&B) 55 years old $O^{7}$ with raw area and exposed infected metals over medial aspect distal lift tibia. (C) Wound debridement and wash. (D) Muscle elevation with preservation of superficial peroneal nerve. (E\&F) Flap inset to defect site. (G)

Application of split thickness skin graft and donor site closed primary over suction drain. (H\&I) 3 days post-operative. (J) 3 weeks post-operative with partial loss of skin graft. (K) 1 month post-operative showing healed raw area. (L) 4 months post-operative. 
Table (1): Age, sex, co-morbidities, smoking and etiology of raw area.

\begin{tabular}{lclccc}
\hline $\begin{array}{l}\text { Patient } \\
\text { No. }\end{array}$ & $\begin{array}{c}\text { Age } \\
\text { (year) }\end{array}$ & Sex & $\begin{array}{c}\text { Co- } \\
\text { morbidities }\end{array}$ & Smoking & Etiology \\
\hline 1 & 20 & Male & - & Yes & Trauma \\
2 & 25 & Male & - & Yes & Trauma \\
3 & 55 & Male & Diabetic & Yes & $\begin{array}{c}\text { Exposed } \\
\text { metals }\end{array}$ \\
4 & 10 & Male & - & No & Trauma \\
5 & 17 & Male & - & No & Post burn \\
6 & 50 & Female & Diabetic & No & Post burn \\
7 & 23 & Male & - & No & Trauma \\
8 & 30 & Male & - & No & Trauma \\
9 & 45 & Male & Diabetic & Yes & Exposed \\
& & & & & metals \\
10 & 40 & Male & - & Yes & Trauma \\
11 & 42 & Male & Diabetic & Yes & Trauma \\
12 & 50 & Female & - & No & Trauma \\
13 & 45 & Female & - & No & Post burn \\
14 & 40 & Female & - & No & Post burn \\
15 & 12 & Male & - & No & Trauma \\
16 & 13 & Male & - & No & Trauma \\
17 & 11 & Male & - & No & Trauma \\
18 & 19 & Male & - & No & Post burn \\
19 & 16 & Male & - & No & Trauma \\
20 & 17 & Male & - & No & Trauma \\
\hline
\end{tabular}

Table (2): Site of defects, flap survival and complications.

\begin{tabular}{|c|c|c|c|}
\hline $\begin{array}{l}\text { Patient } \\
\text { No. }\end{array}$ & Site of defect & Survival of flap & Complications \\
\hline 1 & Right lateral ankle & Survived & - \\
\hline 2 & Left lateral ankle & $\begin{array}{l}\text { Flap not survived } \\
\text { post-operative }\end{array}$ & $\begin{array}{l}\text { Post-operative } \\
\text { necrosis }\end{array}$ \\
\hline 3 & $\begin{array}{l}\text { Left distal tibia } \\
\text { medial aspect }\end{array}$ & Survived & $\begin{array}{l}\text { Partial loss of } \\
\text { graft }\end{array}$ \\
\hline 4 & Right medial ankle & Survived & - \\
\hline 5 & Left anterior ankle & $\begin{array}{l}\text { Flap not viable } \\
\text { intra operative }\end{array}$ & - \\
\hline 6 & Right posterior ankle & Distal necrosis & $\begin{array}{l}\text { Partial loss of } \\
\text { graft }+ \text { distal } \\
\text { necrosis }\end{array}$ \\
\hline 7 & Right Lateral ankle & Survived & - \\
\hline 8 & Left Lateral ankle & Survived & - \\
\hline 9 & Right medial ankle & Distal necrosis & Distal necrosis \\
\hline 10 & Right medial ankle & Survived & - \\
\hline 11 & Right medial ankle & Survived & - \\
\hline 12 & Right posterior ankle & $\begin{array}{l}\text { Proximal } \\
3 / 4 \text { survived }\end{array}$ & Distal necrosis \\
\hline 13 & Right posterior ankle & Survived & - \\
\hline 14 & Right posterior ankle & Survived & - \\
\hline 15 & Right medial ankle & Survived & Partial graft loss \\
\hline 16 & Right medial ankle & Survived & - \\
\hline 17 & Right medial ankle & Survived & - \\
\hline 18 & Left anterior ankle & Distal necrosis & Distal necrosis \\
\hline 19 & Left anterior ankle & Survived & - \\
\hline 20 & Left anterior ankle & Survived & - \\
\hline
\end{tabular}

Table (3): Flap survival and site of area affected around the ankle.

\begin{tabular}{lll}
\hline & & $\mathrm{N}=20$ \\
\hline Survival of flap & Partial loss: - n (\%) & $4(20 \%)$ \\
& Complete loss: - n (\%) & $2(10 \%)$ \\
& Complete survival: - n (\%) & $14(70 \%)$ \\
Area around the ankle & Anterior: - n (\%) & $4(20 \%)$ \\
& Posterior: - n (\%) & $4(20 \%)$ \\
& Lateral: - n (\%) & $4(20 \%)$ \\
& Medial: - n (\%) & $8(40 \%)$ \\
\hline
\end{tabular}

Table (4): Patient evaluation of overall results of operation.

\begin{tabular}{lcc}
\hline & No. & $\%$ \\
\hline Poor & 2 & 10 \\
Fair & 5 & 25 \\
Good & 8 & 40 \\
Very good & 2 & 25 \\
\hline
\end{tabular}

\section{DISCUSSION}

Because of the delicate soft tissue coverage of the ankle and lower third of the leg, tissue defects in this area usually require coverage by flaps [7]. Clinically, several reconstructive procedures have been selected to repair soft tissue defects in these regions, including local cutaneous flaps, pedicled fascial or fasciocutaneous flaps, pedicled muscle flaps, and microsurgical free flaps. However, the applicability of local and pedicled flaps is limited due to their limited reach and reduced amount of soft tissue that can be transported [11].

The use of the proximally based peroneus brevis as a pedicled muscle flap was first described by Pers and Medgyesi in 1973. In 2001, Eren et al., described the use of the distally based peroneus brevis flap for reconstruction around the ankle. This muscle flap is easily raised, whether pedicled proximally or distally [9].

Yang et al., reported that the peroneus brevis muscle flap has been employed for many years as a type II muscle flap according to the classification of Mathes and Nahai for converge of defects in distal third of the leg. This flap allowed for free rotation of the distal portion without transaction of the major pedicle. In 1998, Taylor reclassified the peroneus brevis flap as a type IV muscle flap because of the numerous vascular pedicles. Eren successfully used the peroneus brevis muscle flap with a distally pedicled base and suggested that key to success was preservation of the distal pedicle in the region 3-finger breadth proximal to the tip of the fibula. They concluded that the blood supply of the distally pedicled peroneus brevis muscle flap received retrograde perfusion from the posterior tibial artery. In addition, the distally pedicled peroneus brevis muscle flap receives ante grade perfusion from the peroneal artery, whether the posterior tibial artery contribution is present or absent [12].

Muscle flaps remain often the first choice, when dealing with bone infections associated with osteomyelitis, soft tissue infections, and large cavities [13]. The application of muscle flaps is one of the most effective treatments for bone infection: It not 
only obliterates bone cavities post debridement but also transfers associated blood supply to the recipient area and enhances antibiotics transportation through the muscle flap vessels to the recipient area, thus achieving the aims of infection control and osteomyelitis treatment [10]. In the present study, Males were more than females with average age 24 years. This can be explained by the higher activity in males and the more frequent exposure to risks at work or traffic. Road traffic accidents was the cause in $14(70 \%)$ of cases.

Bajantri et al., noted partial flap necrosis in 5 out of 28 patients. Two distally based flaps suffered minor distal loss, which required debridement and split skin grafting. Three patients, all with flaps used to cover the medial malleolus, lost a sufficient portion of the distal part of the flap to expose the critical underlying skeletal problem, although the actual loss of the flap was less than $3 \mathrm{~cm}$ in all three cases. Two of these defects required further reconstruction with a flap, one with a propeller flap and the other with a small free flap. The third one was managed with a topical negative pressure dressing followed by split skin grafting. They did not recommend this flap for medial malleolar defects [9].

In another study, only 1 flap superficial necrosis developed in the distal parts of the flap, other than that flap, they did not observe any complete or nearly complete flap necrosis, and all defects were reconstructed successfully by the peroneus brevis flap. They suggested that the reliability and survival of the distally based peroneus brevis muscle flap rely on many different parameters. Vascular risk factors, age of patients, arc of rotation and kinking of the pedicle area, inadequate preparation, unneeded tunneling of the flap, as well as tissue trauma due to accidents or irradiation, may negatively influence perfusion of the entire flap [7].

In the present study, we had 2 total flap losses. One was intra operative and the reason was likely a technical mistake during flap elevation. The other was post-operative due to venous congestion. We were dealing with 2 cases with exposed metals and soft tissue infection, they were diabetics, and both developed distal necrosis with no need for further operation. The donor site was closed primarily without tension over tubal drain leaving at the end a thin, rather inconspicuous scar over the lateral aspect of the leg. Patients rated the cosmetic appearance as very good in $5(25 \%)$, good in $7(35 \%)$, fair in $5(25 \%)$ and poor in $3(15 \%)$ of cases.

Kneser et al., observed Postoperative hematoma required surgical revision in three patients from
28 patients in the study [14]. Bach et al., (2007) observed in one patient, a hematoma developed at the donor site, and therefore evacuation of the hematoma was necessary. In our study no postoperative hematoma observed in any of our patients [7].

In prospective study of 10 patients Lorenzetti et al., they noticed that skin grafting performed in the same stage failed in three cases (two of them were diabetic); two cases were managed by daily dressings and healed successfully by secondary intention whereas the third was debrided and regrafted [15]. In our study, all patients grafted in first stage, 3 patients (15\%) developed partial skin graft loss ( 2 cases were diabetics) two cases were managed by daily dressings and healed by secondary intention, whereas the third case was re-grafted.

In another study, by Abd-Al Moktader, he performed open-book splitting to the proximal part of the muscle belly from its superficial outer surface, which increased its width to cover a large defect of up to $12 \mathrm{~cm}$ in length and $10 \mathrm{~cm}$ in width, flap survival was excellent, and partial graft loss in 2 cases healed with dressing. The donor-site scar area also healed nicely, except in 1 case of post burn scar, where it healed by secondary intention [8].

Koski et al., reported that peroneous brevis muscle flap has many advantages in comparison to other reconstructive options. The major advantages are a quick and safe surgery, reliable soft tissue coverage of bone and tendons, with muscle tissue and preservation of major arteries of the leg. Besides, donor-site morbidity is negligible because the preserved peroneus longus muscle will maintain the function of plantar flexion and foot eversion [16].

The reversed sural fasciocutaneuos flap constitutes a reliable and versatile option for coverage of defect around ankle and lower third of the leg. It has the advantage of well-known pedicle, wide arc of rotation, and large dimensions. However, it has the disadvantages of the liability for venous congestion, considerable donor site scarring, loss of sensation of sural nerve distribution over lateral foot and requirement for debulking in most cases [17]. However the reconstruction with reverse sural fasciocutaneous flaps, a widely accepted flap in many centers worldwide, revealed a major complication rate including total and partial flap loss in $16 \%$ of 58 patients. Altogether $50 \%$ of patients had postoperative complications including major and minor problems [5]. 
Compared with the traditional flap or workhorse flap, the peroneal artery perforator flap decreases bleeding, preserves muscle function, has a multiform flap design, and enhances mobility of the flap besides, a peroneal septocutaneous or musculocutaneous perforator stems from the parent vessel, which directly supplies the overlying skin, and the flap helps preserve the peroneal vessel system. Due to these advantages, peroneal artery perforator flaps are a suitable choice for the treatment of chronic lower extremity wounds [18]. According to the present study, we can still say that the peroneous brevis muscle flap has the advantages of minimal donor morbidity, less distal necrosis and easy quick procedure.

Free flaps also play an important role in treating defects of the distal third of lower legs because of in treating large defects of the distal third of the lower legs because of good three-dimensional designs and adequate tissue volume. However, in selected cases, their disadvantages include the need for time-consuming, donor-site morbidity, increased operation time, use of a major vessel of the leg, costly microsurgical techniques. In addition, not all patients are willing or healthy enough to undergo free tissue transfer procedures [10].

\section{Conclusion:}

The study suggests that the peroneus brevis muscle flap is an additional tool for reconstruction of defects around the ankle due to adjacent location, reliability, and the relative simplicity of technique that can be performed in a single stage.

The study showed good overall success of the flap as well as the cosmetic results. There is no functional donor site impairment of the affected extremity due to flap harvest. Function of foot eversion and plantar flexion as well as ankle functionality are maintained due to preservation of the peroneus longus muscle.

\section{REFERENCES}

1- Dockery G.L. and Crawford M.E.: Lower extremity soft tissue and cutaneous plastic surgery, Saunders Limited, 2: 150-300, 2006.

2- Grey H., Williams P. and Bannister L.: Grey's anatomy: the anatomical basis of medicine and surgery. Williams PL., 38: 1212-1215, 1995.

3- Thorne C.H.: Grabb and Smith's plastic surgery, Lippincott Williams \& Wilkins, 2: 100-120, 2013.

4- Rodriguez Collazo E.R., Bibbo C., Mechell R.J. and Arendt A.: The reverse peroneus brevis muscle flap for ankle wound coverage. J. Foot Ankle Surg., 52 (4): 5436, 2013.
5- Ensat F., Hladik M., Larcher L., Mattiassich G. and Wechselberger G.: The distally based peroneus brevis muscle flap; clinical series and review of the literature. Microsurgery, 34: 203-8, 2014.

6- El-Khatib H.A.: The split peroneus muscle flap: A new flap for lower leg defects. J. Plast. Reconstr. Aesthet. Surg., 60: 898- 903, 2007.

7- Bach A. D., Leffler M., Kneser U., Kopp J. and Horch R.E.: The versatility of the distally based peroneus brevis muscle flap in reconstructive surgery of the foot and lower leg. Ann. Plast. Surg., 58: 397-404, 2007.

8- Abd-Al Moktader M.A.: Open-book splitting of a Distally Based Peroneus Brevis Muscle Flap to Cover Large Leg and Ankle Defects. Plast. Reconstr. Surg. Glob Open, 3 (12): e572, 2015.

9- Bajantri B., Bharathi R., Ramkumar S., Latheef L., Dhane S. and Sabapathy S.R.: Experience with peroneus brevis muscle flaps for reconstruction of distal leg and ankle defects. Indian J. Plast. Surg., 46: 48-54, 2013.

10- Hu X.H., Du W.L., Chen Z., Li, M., Wang C. and Shen Y.M.: The application of distally pedicled peroneus brevis muscle flaps and retrograde neurocutaneous accompanying artery flaps for treatment of bony and soft-tissue 3dimensional defects of the lower leg and foot. Int. J. Low Extrem Wounds, 12: 53-62, 2013.

11- Ruan H.J., Cai P.H., Schleich A.R., Fan C.Y. and Chai Y.M.: The extended peroneal artery perforator flap for lower extremity reconstruction. Ann. Plast. Surg., 64: 451-7, 2010.

12- Yang Y.L., Lin T.M., Lee S.S., Chang K.P. and Lai C.S.: The distally pedicled peroneus brevis muscle flap anatomic studies and clinical applications. J. Foot Ankle Surg., 44: 259-64, 2005.

13- Kuokkanen H.O., Tukiainen E.J. and Asko-Seljavaara S.J.O.: Radical excision and reconstruction of chronic tibial osteomyelitis with microvascular muscle flaps. Orthopedics, 11 (25): 137-140, 2002.

14- Kneser U., Brockmann S., Leffler M., Haeberle L., Beier J.P., Dragu A., Unglaub F., Bach A. and Horch R.E.J.: Comparison between distally based peroneus brevis and sural flaps for reconstruction of foot, ankle and distal lower leg: An analysis of donor-site morbidity and clinical outcome. Plast. Reconstr. Aesthet. Surg., 64 (5): 656- 62, 2011.

15- Lorenzetti F., Lazzeri D., Bonini L., Giannotti G., Piolanti N., Lisanti M. and Pantaloni M.: Distally based peroneus brevis muscle flap in reconstructive surgery of the lower leg: Postoperative ankle function and stability evaluation. J. Plast. Reconstr. Aesthet. Surg., 63: 1523-33, 2010.

16- Koski E.A., Kuokkanen H.O. and Tukiainen: Distallybased peroneus brevis muscle flap: A successful way of reconstructing lateral soft tissue defects of the ankle. Plast. Reconstr. Surg., 39: 299-301, 2005.

17- Hassan K.M. and Awadeen A.: Outcome of distally based sural island fascio-cutanous flap for coverage of defects around the ankle and lower leg. AAMJ, Vol. 8, N. 3, 161$181,2010$.

18- Cheng L., Yang X., Chen T. and Li Z.: Peroneal artery perforator flap for the treatment of chronic lower extremity wounds. J. Orthop. Surg. Res., 12: 170, 2017. 